\title{
Decision Confidence, Information Usefulness, and Information Seeking Intention in the Presence of Disconfirming Information
}

\author{
Brandon K. Phillips, Victor R. Prybutok, and Daniel A. Peak \\ University of North Texas, Denton, TX, USA
}

\author{
brandon.phillips@unt.edu; prybutok@unt.edu; peak@unt.edu
}

\begin{abstract}
The increasing use of data visualization for displaying information in a transdisciplinary environment raises issues about client information seeking in the decision-making processes. Field experts and individuals with high confidence tend to seek less information for their decisions than non-experts and individuals who are less confident. This work fills a gap about the effect of the information display format, visual or nonvisual, upon the client's decision. In the context of data visualization and confirmation bias, this work provides needed research on computer aided information seeking in a decision-making, informing environment. Guided by the theories of confirmation bias and cognitive fit, we propose and test a model that investigates the impact of apriori decision confidence on seeking more information and information usefulness. Findings indicate that both information presentation type and confirmation bias affect the decision process of the information seeker. Findings also indicate that overall, the higher the confidence, the less likely users will find disconfirming evidence useful.
\end{abstract}

Keywords: Decision confidence, information presentation, information usefulness, intention to seek further information, confirmation bias, data visualization, business intelligence, information presentation

\section{Introduction}

Computer aided data visualization that facilitate decision making by utilizing Decision Support Systems (DSS) have become part of what we can call the informing environment. This study builds upon the work of (Kahneman \& Tversky, 1972) by addressing the burgeoning need to investigate the phenomenon of a priori beliefs as they relate to decision confidence, information usefulness, and information seeking within the context of different formats for information display. In this work, the applicable transdisciplinary information environment is composed of fac-

Material published as part of this publication, either on-line or in print, is copyrighted by the Informing Science Institute. Permission to make digital or paper copy of part or all of these works for personal or classroom use is granted without fee provided that the copies are not made or distributed for profit or commercial advantage AND that copies 1) bear this notice in full and 2) give the full citation on the first page. It is permissible to abstract these works so long as credit is given. To copy in all other cases or to republish or to post on a server or to redistribute to lists requires specific permission and payment of a fee. Contact Publisher@InformingScience.org to request redistribution permission. tors and influences that affect, enable, and limit the process of informing clients (Cohen, 2009). These visual decision-making systems allows informers (the information providers) and clients (the information receivers and decision makers) to become interconnected by creating rich data visualization to aid in the decision-making process. 
Confirmation bias occurs when the client may focuses on a subset of the data visualization that confirms their preconceived notions and does not directly argue against these pre-established ideas, thus creating layers of complexity and barriers to seeking and using information. Because of this confirmation bias, clients tend to find newly presented information to be less useful, and by extension, are less likely to seek out more information. This is also the case for the clients who begin the decision-making process with a high level of confidence, indicating that they are very familiar with the context of the decision they are asked to make, and again are less likely to find new information useful, or to seek out additional information. Therefore, the question that motivates the present study is: What factors contribute to users seeking intention, and propensity to change their mind in the presence of newly presented disconfirming information?

In the spirit of the philosophy of informing science (Cohen, 2009), we believe the results of this study have transdisciplinary implications for future research, especially in the fields of information systems, human-computer interaction, communication, and the behavioral sciences. This work also provides needed research on information seeking in a decision-making, computer aided informing environment.

Information Systems (IS) scholars have expended significant effort in researching decision making and decision support systems. The quality of decisions depends largely on the quality, quantity and variety of information presented during the decision-making process (Kray \& Galinsky, 2003). With the increase in use of Business Intelligence (BI), and by extension, data visualization techniques, the ability to make decisions based up on the visualization of data is increasingly important in today's technological and business climate. Because of data visualization, vast amounts of complex data can be visualized in ways that intuitively facilitate data-driven decision-making. The aim of these new data visualization techniques is to increase both the speed and effectiveness of computer-based decisions and to drive the data-driven decision-making process. There exists decades of research on the effectiveness of graphical data representation, i.e. graphs over textual information (Dickson, 1977; Mason \& Mitroff, 1973). However, we have seen little inquiry focused on confirmation bias and its effect on information usefulness and seeking intention.

Psychologists also have contributed to bias research in information presentation. For example, studies that examine cognitive bias - thought patterns that inhibit individuals from interpreting information accurately - abound. (Baron, 2000) was instrumental in identifying types of cognitive bias, including hindsight, framing, self-selection, and confirmation bias. In this study, we focus on a specific cognitive bias, known as confirmation bias, because it closely relates to data visualization and the decision-making context. The presence of confirmation bias and the individual's propensity to discount disconfirming evidence (evidence that seems to contradict a previous cognitive assessment) presents many challenges for knowing the proper use of data visualization tools in decision-making. To enable the client to formulate data-driven decisions effectively and efficiently, the informer not only should provide the client with evidence of the confirmation bias, but also should provide evidence to counter it. However, the informer must first understand information bias and its likely consequences when developing data visualizations that will inform the clients. The informer also needs to be aware of this bias when developing visualizations so enabling the client to process visualizations in a useful and effective manner that encourages the client to seek out information and challenge his or her own a priori mental model.

In our rapidly emerging visual data society, adept informers must learn to exploit the relationships among confirmation bias, decision confidence, and visualized data. Many studies have examined confirmation bias; however, few studies exist in IS and fewer have focused on data visualization. In view of the many limitations of earlier visual tools, the newer, more-innovative, multi-dimensional visual tools offer promise for countering effects of confirmation bias in ways not previously feasible - if the visual designers have requisite knowledge and skills. 
This work fills a gap about the effect of the information display format, visual or nonvisual, upon the client's decision. In the context of data visualization and confirmation bias, this work provides needed research on computer aided information seeking in a decision-making, informing environment. Therefore, it is the aim of this study to investigate the phenomenon of confirmation bias as it relates to decision confidence, information usefulness, and information seeking intention. We pose the following research questions:

RQ1: What is the relationship between a priori decision confidence on perceived information usefulness and information seeking intention?

RQ2: What is the role of information presentation type on decision confidence, perceived information usefulness, and information seeking intention?

\section{Literature Review and Hypotheses Development}

Guided by these research questions, we develop an empirical study and survey instrument to examine decision confidence, information usefulness, and intention. Using the lens of confirmation bias theory, we endeavor to enrich informing research and aid practitioners with challenges related to confirmation bias effects on decision-making processes. The following sub-sections discuss factors important to this study.

\section{Cognitive Bias}

Cognitive bias is a pattern of deviation in judgment that occurs in particular situations, which can lead to perceptual distortion, inaccurate judgments, illogical interpretation or what (Kahneman \& Tversky, 1972) call irrationality. Cognitive biases shape our perceptions of reality and interpretation of the world around us, sometimes called a personal worldview. Kahneman and Tversky (1972) first introduced the concept of cognitive biases, while (Baron, 2000) was instrumental in further defining cognitive biases such as framing bias, hindsight bias, self-serving bias, belief bias, fundamental attribution error, and confirmation bias. In this study, we focus on confirmation bias and its effects on decision confidence, information usefulness, and information seeking intention, as it presents the most challenges associated with decision-support systems and informing research.

\section{Confirmation Bias}

Confirmation bias is the tendency to search for or to interpret information in a way that confirms preconceptions. It involves the pre-emptive discounting, disbelieving, or ignoring of evidence that threatens to disconfirm previously-held opinions or beliefs (Kahneman \& Tversky, 1972). In the presence of confirmation bias, users are only interested in presented information that will align with their own cherished convictions. Therefore, confirmation bias can lead individuals not to review information even if presented to them appropriately, leading to inaccurate and irrational decision making (Kahneman \& Tversky, 1972).

Evidence for the existence of the confirmatory bias phenomenon is supported in the psychology literature (Bruner \& Potter, 1964; Darley \& Gross, 1983; Haverkamp, 1993; Lord, Ross, \& Lepper, 1979; Pious, 1991). Our study builds upon Khaneman and Tversky's (1972) seminal research on confirmation bias, extending it into the modern data visualizations that clients now commonly view in the $21^{\text {st }}$-century informing environment. Studies show that confirmation bias continues to be a primary factor that affects the quality of business decision making, such that biased decisions can accumulate to the point that they both negatively and significantly impact firm profitability (Barber \& Odean, 1999). Thus, confirmation bias is a pervasive human idiosyncrasy that taints individual judgment concerning information that does not fit personal preconceptions - a condition that we believe well-designed data visualizations can ameliorate. Although 
biases vary from person to person, a strong confirmation bias can crush any client proclivity to seek additional, essential, decision-making information.

\section{Information Seeking}

Information seeking plays a vital role in the decision-making process, as it speaks to the client's intention to seek out more information than was provided with the original task or decision model. According to marketing literature, a driving factor affecting the client's informationseeking intention is self-confidence. Indicating that the more confident the client is in their position and mental model, then the less likely they will be to seek additional information (Locander \& Hermann, 1979). Additionally, (Kuhlthau, 1991) found that the client's perception of the usefulness of the information that they receive affects further seeking intention. Within the context of confirmation bias, information seeking is pivotal to understanding how biases affect the client's ability to understand and process information within the informing environment. This study focuses on how pre-confidence, post-confidence, and perceived usefulness of disconfirming information affects the client's seeking intention and ultimately the client's propensity to change their mind (vote).

\section{Disconfirming Information and Hypothesis Preservation Bias}

Disconfirming information is an important tool psychologists and sociologists use to combat a type of confirmation bias called hypothesis preservation bias (Johnston, 1996). Because clients naturally expect to receive confirming information, merely presenting information is not sufficient to elicit or reinforce a confirmation bias (Evett, Devine, Hirt, \& Price, 1994). Informers must first establish a premise; then they can willfully bias (i.e., manipulate) the information so that the likely outcomes either will confirm or will disconfirm the original premise. Although clients instinctively discount disconfirming information, the informer may systematically present disconfirming information until the targeted client no longer preserves the original hypothesis (bias), such as combating a stereotype (Johnston, 1996).

In a business context, a negative consequence of confirmation bias is the increased inability to change the decision - a condition that occurs when the client embraces an abnormally-high decision confidence (Griffin \& Varey, 1996). Because data visualization is transdisciplinary, research into un-biasing a client across multiple areas suggests using disconfirming evidence (counter arguments) to elicit a re-examination of the all evidence affords clients the opportunity to change their mind. (Kahneman \& Tversky, 1972; Russo \& Schoemaker, 1992). Nevertheless, research suggests that once an individual forms a belief about something, the person typically finds it difficult to change that belief (Hoch \& Deighton, 1989). Even so, if a client perceives the disconfirming stimulus to be useful, the possibility of changing the belief increases (Einhorn \& Hogarth, 1978).

\section{Data Visualization}

Visualization is "a graphical representation of data or concepts" (Few, 2007). Data visualization supports effective decision making because it allows vast amounts of data to be interpreted through intuitive, visual perceptions that do not require mental, numerical processing. Visual impressions are processed in about 50 milliseconds, which suggests that they are both pre-cognitive and instantaneous, (Lindgaard, Fernandes, Dudek, \& Brown, 2006), and therefore much faster than cognitively-processed tabular or textual data (Few, 2007). Modern organizations access vast amounts of data to make decisions that they need to synthesize and analyze quickly. The incessant need to process data into good decisions is leading relentlessly to the pursuit of better data presentation strategies and thus better data visualization techniques (Few, 2007). 
Data Visualization plays a vital role in Business Intelligence (BI) system strategies, where BI facilitates faster, smarter, data-driven decisions in the corporate world (Hedgebeth, 2007). The explosion of data visualization techniques, corporate investment in BI, and associated research all indicate that visualization is worth the time and expense to achieve better business decisions and outcomes (Baker, Jones, \& Burkman, 2009). The earliest IS research studies that investigated visual data representations, the so-called Minnesota Experiments (Dickson, 1977), examined the relationship between system design characteristics and the graphical representation of data, leading to decision outcomes that vary with type of information presentation. In the spirit of the Minnesota Experiments, this study examines decision outcomes that vary by type of presentation, but further investigates the effects of data visualizations not possible with the technology of that time.

\section{Cognitive Fit}

Cognitive fit and information presentation have been fruitful research areas in the context of DSS and the decision-making process, such as effects of simple graphical and tabular data representation (Dickson, 1977), effects of data representation on decision-making performance (Dennis \& Carte, 1998), and what users or clients deem to be useful information presentations (Hong, Thong, \& Tam, 2004). (Kolata, 1982) found that graphic displays exercised the uniquely human ability to discern meaningful patterns in the data, and to perceive patterns that otherwise would have remained unseen. (Vessey \& Galletta, 1991), who proposed cognitive fit as a response to the graph versus table research, suggested that a positively perceived presentation format not only increased task performance, but also enhanced the perceived usability of the visuals.

Thus, information presentation format is an important part of the decision-making process, such that task characteristics, client characteristics, information presentation, and mental representation are strong indicators of decision-making outcomes (Kelton, Pennington, \& Tuttle, 2010). Cognitive fit evolved from Task-Technology Fit, as it proposes that the task, whether graphical or tabular, can display the same underlying information. However, due the distinct characteristics of graphical or tabular displays individual clients interpreted them differently. Therefore, the task solution is dependent upon the fit of the client's mental model with the information presentation. (Vessey \& Galletta, 1991) indicated that when the information presentation type matched the questions, task performance and perceived usefulness increased. (Lurie \& Mason, 2007) proposed a cognitive-fit model to explain the implications of visual representation in the decision-making process. Their model examines the visual perspective and information context of the data representation: when a representation is perceived as valuable or effective, the user is more inclined to trust it and consider it useful (Li \& Yeh, 2010).

\section{Decision Confidence and the Intention to Seek Further Information}

Decision Confidence is relevant to the relationship between buyer uncertainty and information seeking within the marketing literature. Researchers discovered that the reason buyers seek information before purchasing is to raise the confidence level and reduce uncertainty concerning their purchasing decisions (Cox, 1967; Hansen, 1972). For example, the more uncertainty or the lower confidence level the individual exhibits, the more likely they will be to seek out more information (Lanzetta, 1963). IS research also indicates that decision confidence affects perception, interpretation, use of data, and ultimately the outcome decision. The levels of decision confidence and perceived expertise are highly correlated, further solidifying the position that higher decision confidence can lead to oversight, and incorrect interpretation of data, as the individual's preconceptions overshadow the data in front of them. 


\section{Information Presentation Then and Now}

The quality of information presentation can play a powerful role in the decision outcome. In early IS research that examined users' attitudes about interface design and user confidence in the quality of decisions made, (DeSanctis \& Gallupe, 1984) cited "viewer preference" as a major dependent variable. Others explored the use of graphical displays to improve decision performance, which were found to be more effective and useful than tabular displays (Benbasat \& Schroeder, 1977; Lucas, 1981; Zmud, 1979). However, (DeSanctis \& Gallupe, 1984) reported that certain features that make a graph more visually appealing, such as color, shading, realism, and complexity, may actually diminish user comprehension accuracy.

We recognize that about thirty years have elapsed since these early studies, and that Data Visualization and BI have emerged amid a more-advanced technology, a more-transdisciplinary client base, a more-interactive informing environment, a multitude of different display types, and a higher societal-level of computer literacy. Data Visualization, in the context of Business Intelligence systems, relies heavily on the current diverse graphical display of sundry types of data, as well as sophisticated visual aids, to facilitate quality decision-making. Therefore, we believe it imperative that data visualizations convey information not just accurately, but also display information intuitively and in a form that is easy to comprehend - without distraction or confusion. An additional goal is to display information in such a way that the informing environment is more visually accessible, thus, enhancing the decision making process, and improving the decision outcomes.

In the context of this study, we examine how respondents interpret identical data presented to them both visually and non-visually. We examine perceptions of presentation usefulness and lead respondents to seek out more information.

\section{Conceptual Model}

The literature on seeking intention and decision confidence levels support the following model and our hypotheses shown in Table 1 and Figure 1 to investigate the operative relationships. Our theoretical model of the informing environment examines visual and non-visual decisions in the presence of disconfirming information. We note that, although we conducted the study with business respondents, the model is transdisciplinary in nature.

\begin{tabular}{|l|l|}
\hline Table 1: Hypotheses \\
\hline & \\
\hline H1 & Post vote confidence will have a negative effect on changed vote \\
\hline H2 & Post vote yes responses will have a negative effect on changed vote \\
\hline H3 & Percieved usefulness of the evidence will have a positive effect on changed vote \\
\hline H4 & Percieved usefulness of the evidence will have a positive effect on seek intention \\
\hline H5 & Pre vote confidence will have a negative effect on seek intention \\
\hline H6 & Pre vote yes responses will have a negative effect on seek intention \\
\hline H7 & Evidence presented using visual representations will have a negative effect on seek intention \\
\hline H8 & Seek intention will have a positive effect on changed vote \\
\hline
\end{tabular}




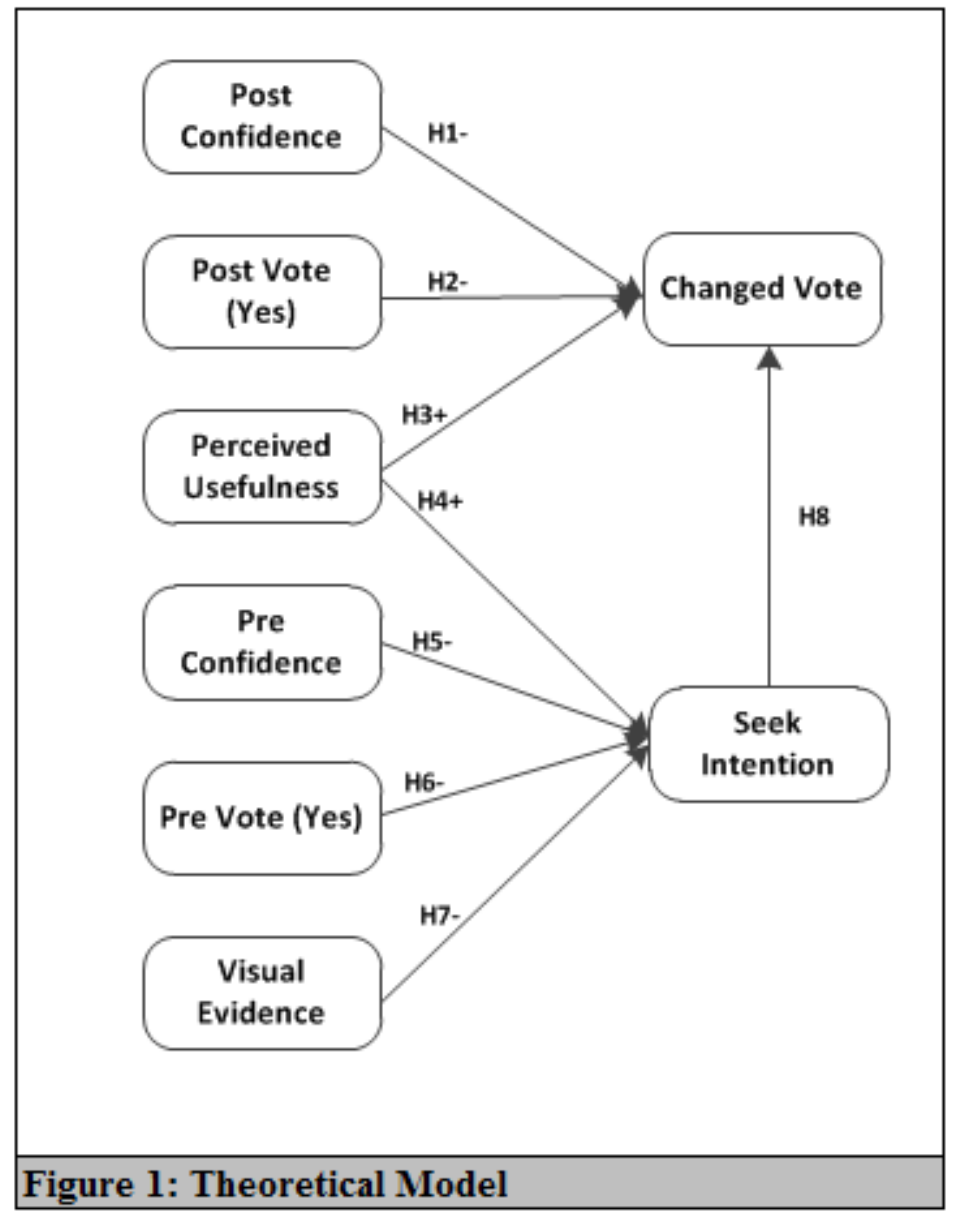

\section{Method}

Our survey instrument validates scales from the literature that is generalizable to a transdisciplinary informing environment. The respondents were presented with a scenario about laptops in the classroom and asked to vote on whether or not they believed laptops should be used in the classroom. Subsequently, we asked them to rate their level of decision confidence. Each respondent received the same scenario primer.

Next, respondents received disconfirming evidence with the intention to test confirmation bias. Evidence presented was contrary to the respondent's previous vote. Then, we randomly assigned respondents to one of two surveys (see Appendices A \& B for the surveys) that contained either visual disconfirming evidence or non-visual disconfirming evidence. After reviewing the disconfirming evidence, we asked respondents to rate the usefulness of the evidence presented, as well as their intention to seek out more information concerning the topic of laptop use in the classroom. Finally, we asked the respondents to re-vote, in light of the presented disconfirming evidence, and to once more rate their decision confidence level. Figure 2 shows our process model and the sequence of events in the survey flow.

In developing the survey instrument, we adapted scales and constructs from previously validated scales found in the sources shown in table 2 below, and contextualized the items to this study. We piloted the survey using an expert panel of IS faculty and doctoral students to obtain feedback, to ensure survey validation, and to gauge the average time required to complete it. We incorporated comments and suggestions of the expert panel into the final version of the survey, which we dis- 
tributed to student respondents. We had $\mathrm{PhD}$ students familiar with survey development and the context of the study give feedback for readability and organization. Table 2 contains the constructs and sources we contextualized for use in this study.

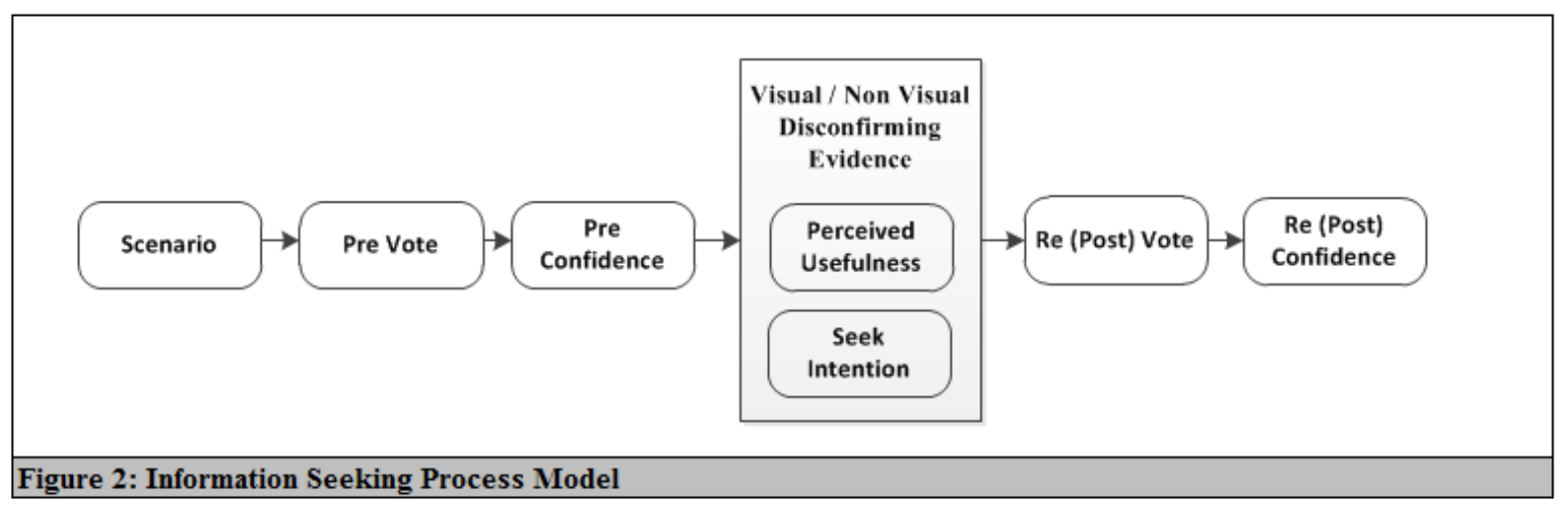

\begin{tabular}{|c|c|c|}
\hline Construct & Questions & Adapted From \\
\hline \multirow[t]{3}{*}{ Pre and Post Confidence } & I am confident in my decision. & \multirow{3}{*}{$\begin{array}{c}\text { Aldag and Power } \\
\text { (1986) }\end{array}$} \\
\hline & I am confident I made the correct decision. & \\
\hline & I feel confident about my vote. & \\
\hline \multirow[t]{5}{*}{ Usefulness } & I find the information useful. & \multirow{5}{*}{ Li and Yeh (2010) } \\
\hline & The information improves the effectiveness of my decision making. & \\
\hline & The information makes it easier to make my decision. & \\
\hline & The information is useful to me. & \\
\hline & The information is useful in my decision making. & \\
\hline \multirow[t]{4}{*}{ Seeking Intention } & I would like to seek more information on the subject of laptops in the classroom. & \multirow{4}{*}{ Kahlor (2007) } \\
\hline & I would like to look for more evidence related to laptop use in the classroom. & \\
\hline & I would be interested in examining more information related to laptop use in the classroom. & \\
\hline & I would be interested in seeing more evidence related to laptop use in the classroom & \\
\hline
\end{tabular}

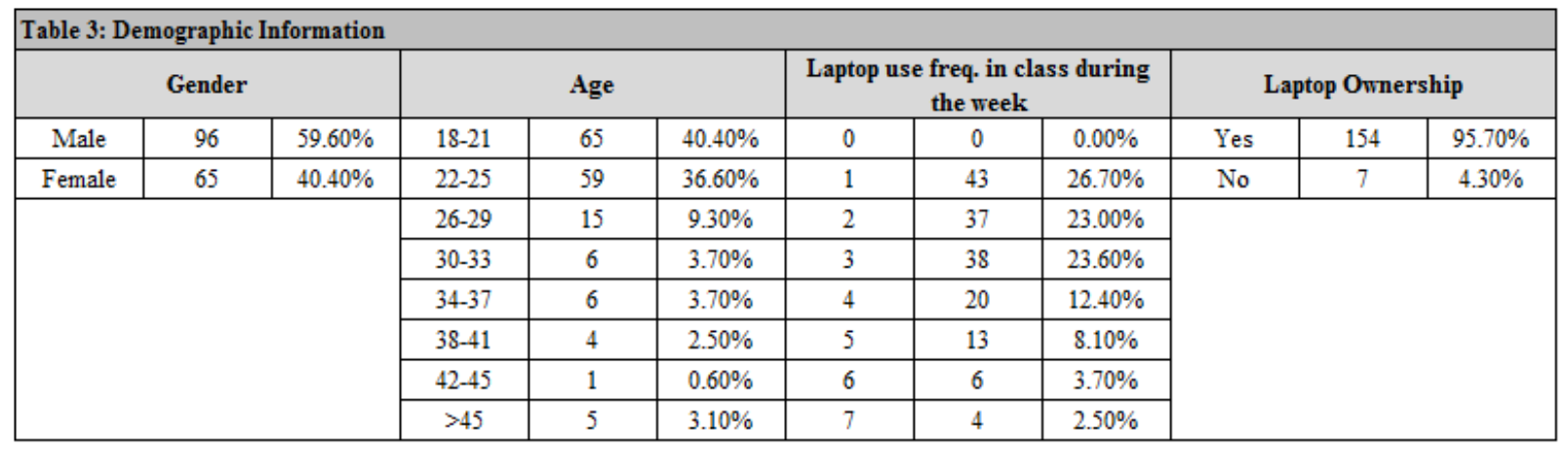

We collected data from the survey instrument administered online to undergraduate and graduate students in the college of business at a large southwestern university in the US. Out of 223 possible respondents, 186 took the survey. Of these, we removed 25 surveys due to incompleteness or because the respondents rushed through the survey in less than three minutes, yielding 161 usable responses, or an $86 \%$ usable response rate. Table 3 contains demographic information from the respondents. The data shows that an overwhelming percentage of the student have laptops (96\%) and they use them with some frequency within the class during a week (over $50 \%$ use them in class 3 or more times per week). 


\section{Results}

This section presents the analysis of reliability, convergence and discriminant validity and hypotheses testing. In order to test our proposed model, we used SPSS statistical software for regression analysis. First, we tested the reliability of the four constructs in the model; Table 2, which indicates the Cronbach's alpha for these constructs, demonstrates that the alphas scores well within the accepted reliability range. In this context, a minimum value of 0.7 for Cronbach's alpha is desired (Nunnally \& Bernstein, 1994); values less than 0.6 indicate a lack of internal validity, while values between 0.8 and 0.9 are satisfactory (Henseler, Ringle, \& Sinkovics, 2009). All of our results demonstrate Cronbach's alpha scores greater than 0.88 , indicating satisfactory internal reliability.

Table 4 shows the factor analysis, results, containing factor loadings all above the recommended 0.7 threshold (Henseler et al., 2009). Our results demonstrate all values greater than 0.83 . Factor loadings greater than 0.8 indicate good discriminate validity (Henseler et al., 2009), while we have removed values less than 0.3 from the table. The results indicate high values of convergence and discriminant validity, where all of values exceed 0.7 .

\begin{tabular}{|c|c|c|c|c|c|c|c|c|}
\hline Table 4: Descriptive Statistics, Factor Analysis, Cronbach's Alpha \\
\hline Scale Item & Mean & Std. & Variance & Cronbach & \multicolumn{3}{|c|}{ Factor Correlations } & \\
\cline { 5 - 9 } & & Der. & & Alpha & Pre-conf & Use & Seek & Post-conf \\
\hline Preconf1 & 6.25 & 0.793 & 0.628 & & 0.945 & & & \\
Preconf2 & 6.21 & 0.745 & 0.555 & 0.948 & 0.942 & & & \\
Preconf5 & 6.29 & 0.754 & 0.568 & & 0.954 & & & \\
\hline Use1 & 5.24 & 1.239 & 1.535 & & & 0.769 & & \\
Use2 & 4.6 & 1.446 & 2.091 & & & 0.766 & & \\
Use3 & 4.51 & 1.467 & 2.151 & 0.881 & & 0.813 & & \\
Use4 & 4.8 & 1.55 & 2.401 & & & 0.896 & & \\
Use5 & 4.84 & 1.559 & 2.432 & & & 0.837 & & \\
\hline Seek1 & 4.69 & 1.693 & 2.865 & & & & 0.897 & \\
Seek2 & 4.86 & 1.606 & 2.578 & & & & 0.944 & \\
Seek3 & 4.94 & 1.627 & 2.646 & 0.948 & & & 0.928 & \\
Seek4 & 4.83 & 1.523 & 2.32 & & & & 0.931 & \\
\hline Postconf1 & 5.831 & 1.278 & 1.636 & & & & & 0.894 \\
Postconf2 & 5.73 & 1.306 & 1.707 & 0.975 & & & & 0.919 \\
Postconf5 & 5.778 & 1.303 & 1.698 & & & & & 0.925 \\
\hline
\end{tabular}

\section{Hypotheses Testing}

The model contains eight testable hypotheses. We examined two outcome variables: changed vote and information seeking intention. Using SmartPLS, a Partial Least Squares (PLS) analysis solution we tested the eight hypotheses (Ringle, Wende, \& Will, 2005). PLS is an appropriate tool for studies early in the exploratory stage (Ainuddin, Beamish, Hulland, \& Rouse, 2007), as with the current study. 


\section{Analysis}

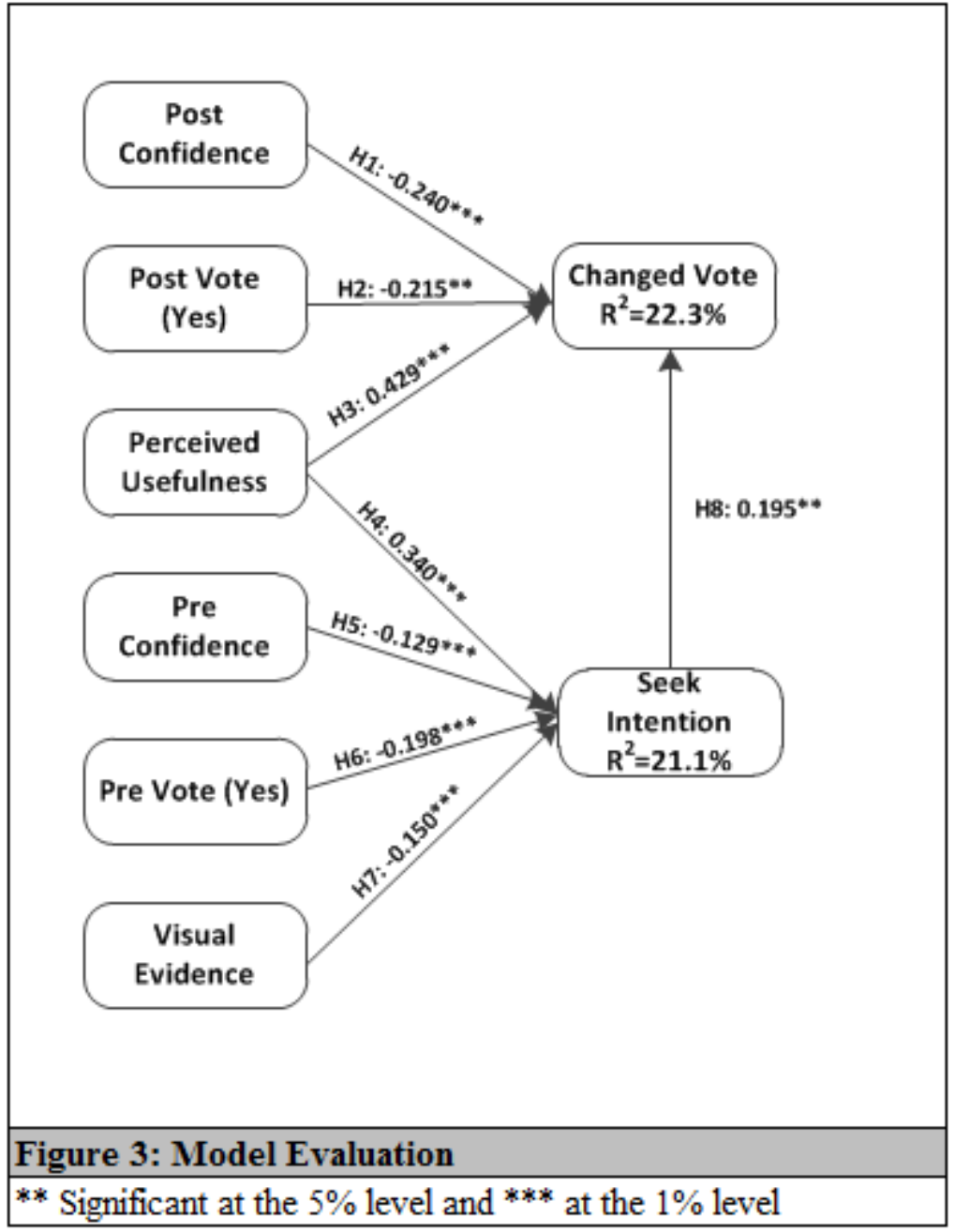

\begin{tabular}{|l|l|l|}
\hline \multicolumn{1}{|l|}{ Table 5: Hypotheses Evaluation } & Hypothesis & Evaluation \\
\hline H1 & Post vote confidence will have a negative effect on changed vote & Supported $* * *$ \\
\hline H2 & Post vote yes responses will have a negative effect on changed vote & Supported $^{* *}$ \\
\hline H3 & Percieved usefulness of the evidence will have a positive effect on changed vote & Supported $* * *$ \\
\hline H4 & Percieved usefulness of the evidence will have a positive effect on seek intention & Supported $* * *$ \\
\hline H5 & Pre vote confidence will have a negative effect on seek intention & Supported $* * *$ \\
\hline H6 & Pre vote yes responses will have a negative effect on seek intention & Supported $* * *$ \\
\hline H7 & Evidence presented using visual representations will have a negative effect on seek intention & Supported \\
\hline H8 & Seek intention will have a positive effect on changed vote & Supported $* *$ \\
\hline$* *$ Significant at the 5\% level and $* * *$ at the $1 \%$ level & \\
\hline
\end{tabular}

The final model evaluation shown in Figure 3 and hypotheses evaluation in Table 5 reveal a strong negative relationship between the post-experiment confidence of the revote and the likelihood of a vote or decision change (H1). There also exists a negative relationship between clients 
who voted yes in the revote and the likelihood of a vote change (H2). We observe a positive relationship between perceived information usefulness and likelihood of vote change (H3). Related to the outcome variable of seeking intention our results reveal a strong positive relationship between perceived information usefulness and the clients seeking intention (H4). However, pre-confidence (H5), pre-vote of "yes" (H6), and disconfirming information presented visually (H7) all indicated negative relationships related to client information seeking intention. Our final hypothesis (H8) reveals a positive relationship between client information seeking intention and propensity to change one's vote, indicating that as information seeking intention increases, so does the likelihood for a vote change. These results are in agreement with the literature review in this subject and our hypothesis assumptions.

\section{Discussion}

Our results show that in the presence of disconfirming evidence, information seeking intention is influenced by perceived usefulness, pre-confidence, pre-evidence vote, and the visual format of the information. This study has aimed to answer its research questions; we believe we have met this challenge. Restating RQ1: What is the relationship between a priori decision confidence on perceived information usefulness and information seeking intention?

Answering RQ1, the results of this study indicate that a priori decision confidence has a negative effect on information seeking intention and that there were no statistical significant relationships between a priori decision confidence and information usefulness. Therefore, in the presence of disconfirming information, and as a user's pre confidence increases, the likelihood that the user will seek out additional information decreases. This finding suggests that confirmation bias does in fact play a role in the individual's decision-making process, and ultimately influences their information seeking intention behavior. Now, recall RQ2: What is the role of information presentation type on decision confidence, perceived information usefulness, and information seeking intention?

Answering RQ2, results indicate that information presentation type has a negative relationship with information seeking intention, revealing that when information is presented in a visual format, the user is not led to seek additional information. Contrastingly, when information is presented in a textual format, the user is led to seek additional information. Surprisingly, the way in which the information was presented in our study did not have a statistically significant effect on perceived information usefulness or user confidence.

Furthermore, perceived usefulness shows a positive relationship with information seeking intention, while the other constructs indicated a negative relationship. These findings align with research on information seeking intention that involves cognitive fit and confirmation bias. Cognitive fit theory posits that a fit must occur between the task and the client. Our findings show a "fit" is created that enhances task performance and decision-making (Dennis \& Carte, 1998). Our study results indicate that, based upon: 1) the visual or non-visual nature of the presentation and 2 ) the client finding the information useful creates a fit that increases seeking intention, as well as propensity to change one's vote.

Results concerning pre-confidence in the client's stance on their initial vote were negatively related to information seeking intention, additionally, post-evidence vote confidence was also negatively related to changing one's vote, indicating that clients with high pre- or post-confidence, were less likely to seek out additional information or change their mind. This is in accordance with the literature and research on confirmation bias. When these biases exist, the client is not easily persuaded to change their mind or seeking intention when high confidence exists indicating that a pre-decision bias or predisposition exists in their mental model. Finally, the relationship between seeking intention and changing one's vote indicates that as seeking intention is in- 
creased, so does the propensity for the client to change their vote. After examining the results of the study we begin to see what influences clients to change their opinion or increase their information-seeking intention in a disconfirming, informing environment. Our results indicate that highly confident clients are less likely to seek or change their opinion, while those that find the information useful are more likely to engage in further information-seeking behavior and have a greater chance of changing their opinion.

\section{Limitations}

This study sampled university students in a class-based setting that resulted in the respondents being from a narrow age range and from primarily business-oriented majors. The population was further limited to being from primarily a North American English-speaking culture. Despite these limitations, this sample population captures the perceptions of individuals who will be the future users and consumers of data visualizations. The age range of individuals captured in this sample are younger and therefore more visual than previous generations, simply because technology becomes more infused into many facets of each succeeding generations' lives, such that this most recent generation is nearly constantly connected to the informing environment.

\section{Implications}

The effects of information presentation type is important not only to researchers but to the practitioner as well. Our research indicated that overall, the higher the confidence of the user, the less likely they were to find disconfirming evidence useful. This indicates that the existence of confirmation bias can influence the perceived usefulness of information. Our results also indicate that the usefulness of the information relates to the intention of the user to seek more information; this relationship was stronger with the non-visual evidence group. These factors are advantageous to the visualization designer when developing data visualization tools that will facilitate BI and DSS.

Practitioners also should be aware of the effect that confirmation bias has on decision-making and data interpretation, in order to mitigate its negative effects and to encourage more un-biased, and accurate decision-making processes. These results indicate that some occasions may be better served by the use of non-visual data to facilitate the decision-making as opposed to visual data; this could further be explored in a practical sense in order to avoid confusion by the overuse of graphics and visual aids used to facilitate client decision-making processes in a visually informing environment. This study has transdisciplinary implications as information seeking intention is an important area of research in multiple disciplines including psychology, marketing and information science, in addition to IS research. Our model allows examining the informing environment in different contexts because of the transdisciplinary nature of the model.

Our experiment provides empirical evidence of the connection between confirmation bias and information seeking intention. We believe this connection represents an important expansion of Khaneman and Tversky's (1972) work into the informing science framework. Additionally, this work provides a foundation for future research addressing the development of computer aided decision-making tools. Future research is likely to cross transdisciplinary boundaries in order to explore the connection between informers and client in an informing environment.

\section{Conclusion}

This research fills an important gap in the literature regarding effects of data visualization on computer-aided decision-making in an informing environment. It builds on the work of (Kahneman \& Tversky, 1972) to address this gap in confirmation bias research related to data 
visualization, the effects of these biases on perceived usefulness and information seeking intention.

Based on our findings, we first conclude that quality data visualization is not only facilitates uncontroversial decisions, but also mitigates biased decisions, and thus quality data visualization serves as a catalyst for better decision making. Although unchallenged cognitive biases (specifically, confirmation bias) negatively affect the decision-making process, we find the use of welldesigned, visualized, disconfirming information induces the client to seek additional information that can adjust their mental model to improve the quality of the decision. We believe practitioners intuitively sense this reality, because we observe industry incorporating data visualization tools that integrate big data into BI systems. Furthermore, practitioners have operationalized the implications of our second conclusion that data visualization is easier to process mentally than the equivalent information displayed as textual data. This visual alternative presents a new perspective on disconfirming evidence and our results show such presentation is useful for reconsidering decisions and adjusting mental models.

Coincidentally, the technology of data visualization is maturing at the same time as new generations of visual-technology-savvy young adults are maturing. This nexus of a changing technology and changing population presents researchers with an opportunity to develop the strategies of data visualization with a fresh group of domain-literate users. In summary, data visualization supports better decisions, helping informers' present clients with either confirming or disconfirming information within the informing environment that is relevant to decision processes. We feel these results are transdisciplinary in nature and provide opportunities to examine and educate in differing informing environments.

\section{Future Research}

Future research could further explore this relationship between non-visual evidence and usefulness, to examine if there is in fact some preference to the type of information that individuals prefer to have in a non-visual and visual format. This future research would further extend our findings and enhance the much needed research stream in confirmation bias and information seeking intention. In addition, a future study could utilize also a more polarizing or controversial scenario in order to further test this model. This polarizing treatment would allow for further exploration of confirmation bias as an extension of this study and continue the necessary research in this area. Finally, in accordance with the confirmation bias literature we provided respondents with only disconfirming evidence relative to their opinion in order to examine the confirmation bias effect. Future work, could present clients with both confirming and disconfirming evidence to examine the differences between the elicited responses to advance confirmation and information seeking intention research. While we did not look at individual client differences in this study, it may be of interest to explore the individual characteristic differences of the client to understand, further, their pre-decision biases, and motivations. These individual differences are paramount to understanding the individual decision maker and the preconceptions, biases and attributes they bring to the decision making process. Not only would this further advance our work, but it would further advance our contribution to the research stream by bringing to light specific attributes of clients in an informing environment that need to be accounted for in order to limit biases, and enhance the usability and outcomes of data visualizations, (Kahlor, 2007). 


\section{References}

Ainuddin, R. A., Beamish, P. W., Hulland, J. S., \& Rouse, M. J. (2007). Resource attributes and firm performance in international joint ventures. Journal of World Business, 42(1), 47-60.

Aldag, R. J., \& Power, D. J. (1986). An empirical assessment of computer-assisted decision analysis. Decision Sciences, 17(4), 572-588.

Baker, J., Jones, D., \& Burkman, J. (2009). Using visual representations of data to enhance sensemaking in data exploration tasks. Journal of the Association for Information Systems, 10(7), 533-559.

Barber, B. M., \& Odean, T. (1999). The courage of misguided convictions: The trading behavior of individual investors. Financial Analysts Journal, 55(6).

Baron, J. (2000). Thinking and deciding: Cambridge University Press.

Benbasat, I., \& Schroeder, R. G. (1977). An experimental investigation of some MIS design variables. MIS quarterly, 1(1), 37-49.

Bruner, J. S., \& Potter, M. C. (1964). Interference in visual recognition. Science, 144(3617), 424-425.

Cohen, E. B. (2009). A philosophy of informing science. Informing Science: the International Journal of an Emerging Transdiscipline, 12, 1-15.

Cox, D. F. (1967). Risk Taking and information handlining in consumer behavior: Division of Research, Graduate School of Business Administration, Harvard University Boston.

Darley, J. M., \& Gross, P. H. (1983). A hypothesis-confirming bias in labeling effects. Journal of Personality and Social Psychology, 44(1), 20-33.

Dennis, A. R., \& Carte, T. A. (1998). Using geographical information systems for decision making: Extending cognitive fit theory to map-based presentations. Information Systems Research, 9(2), 194203.

DeSanctis, G., \& Gallupe, B. (1984). Group decision support systems: a new frontier. ACM SIGMIS Database, 16.2, 3-10.

Dickson, G. W. (1977). Research in management information systems: The Minnesota experiments. Management Science, 23(9), 913-924.

Einhorn, H. J., \& Hogarth, R. M. (1978). Confidence in judgment: Persistence of the illusion of validity. Psychological review, 85(5), 395.

Evett, S. R., Devine, P. G., Hirt, E. R., \& Price, J. (1994). The role of the hypothesis and the evidence in the trait hypothesis testing process. Journal of Experimental Social Psychology, 30(5), 456-481.

Few, S. (2007). Data Visualization: Past, Present, and Future. IBM Cognos Innovation Center.

Griffin, D. W., \& Varey, C. A. (1996). Towards a consensus on overconfidence. Organizational Behavior and Human ..., 65(3), 227-231.

Hansen, F. (1972). Consumer choice behavior: A cognitive theory: Free Press New York.

Haverkamp, B. E. (1993). Confirmatory bias in hypothesis testing for client-identified and counselor selfgenerated hypotheses. Journal of Counseling Psychology, 40(3), 303-315.

Hedgebeth, D. (2007). Data-driven decision making for the enterprise: an overview of business intelligence applications. VINE, 37(4), 414-420.

Henseler, J., Ringle, C., \& Sinkovics, R. (2009). The use of partial least squares path modeling in international marketing. Advances in International Marketing (AIM), 20, 277-319.

Hoch, S. J., \& Deighton, J. (1989). Managing what consumers learn from experience. The Journal of Marketing, 53(2), 1-20. 
Hong, W., Thong, J. Y., \& Tam, K. Y. (2004). The effects of information format and shopping task on consumers' online shopping behavior: A cognitive fit perspective. Journal of Management Information Systems, 21(3), 149-184.

Johnston, L. (1996). Resisting change: information - seeking and stereotype change. European Journal of Social Psychology, 26(5), 799-825.

Kahlor, L. A. (2007). An augmented risk information seeking model: The case of global warming. Media Psychology, 10(3), 414-435.

Kahneman, D., \& Tversky, A. (1972). Subjective probability: A judgment of representativeness. Cognitive psychology, 3.3, 430-454.

Kelton, A. S., Pennington, R. R., \& Tuttle, B. M. (2010). The Effects of Information Presentation Format on Judgment and Decision Making: A Review of the Information Systems Research. Journal of Information Systems, 24(2), 79-105.

Kolata, G. (1982). Computer graphics comes to statistics. Science (New York, N.Y.), 217(4563), 919-920.

Kray, L. J., \& Galinsky, A. D. (2003). The debiasing effect of counterfactual mind-sets: Increasing the search for disconfirmatory information in group decisions. Organizational Behavior and Human Decision Processes, 91(1), 69-81.

Kuhlthau, C. C. (1991). Inside the search process: Information seeking from the user's perspective. Journal of the American Society for Information Science, 42(5), 361-371.

Lanzetta, J. T. (1963). Information acquisition in decision making. Motivation and social interactioncognitive determinants, 239-265.

Li, Y.-M., \& Yeh, Y.-S. (2010). Increasing trust in mobile commerce through design aesthetics. Computers in Human Behavior, 26(4), 673-684.

Lindgaard, G., Fernandes, G., Dudek, C., \& Brown, J. (2006). Attention web designers: You have 50 milliseconds to make a good first impression! Behaviour \& information technology, 25(2), 115-126.

Locander, W. B., \& Hermann, P. W. (1979). The effect of self-confidence and anxiety on information seeking in consumer risk reduction. Journal of Marketing Research, 16(2), 268-274.

Lord, C. G., Ross, L., \& Lepper, M. R. (1979). Biased assimilation and attitude polarization: The effects of prior theories on subsequently considered evidence. Journal of Personality and Social Psychology, 37(11), 2098-2109.

Lucas, H. C. (1981). An Experimental Investigation of the Use of Computer-Based Graphics in Decision Making. Management Science, 27(7), 757-768.

Lurie, N. H., \& Mason, C. H. (2007). Visual representation: Implications for decision making. Journal of Marketing, 71(January), 160-177.

Mason, R. O., \& Mitroff, II. (1973). A program for research on management information systems. Management science, 19(6), 475-488.

Nunnally, J. C., \& Bernstein, I. H. (1994). Psychometric theory. 1994. McGraw, New York.

Pious, S. (1991). Biases in the assimilation of technological breakdowns: Do accidents make us safer? Journal of Applied Social Psychology, 21(13), 1058-1082.

Ringle, C. M., Wende, S., \& Will, A. (2005). SmartPLS 2.0 (beta): Hamburg, Germany.

Russo, J. E., \& Schoemaker, P. J. H. (1992). Managing overconfidence. Sloan Management Review, 33.2, $7-17$.

Vessey, I., \& Galletta, D. (1991). Cognitive Fit: An Empirical Study of Information Acquisition. Information Systems Research, 2(1), 63-84.

Zmud, R. W. (1979). Individual differences and MIS success: A review of the empirical literature. Management Science(10). 


\section{APPENDIX A}

\section{Information Seeking Survey Group Instrument (Visual Group)}

A. Please read the following scenario related to the use of computers in classroom.

Many students bring their personal computing devices (e.g. laptops) to their classes and use them during lectures. Some professors feel that the unauthorized use of personal laptops by students during class time is disruptive to their learning. Some students and professors feel that the use of personal laptop actually enhances learning experience. Imagine that you are member of a student government body at the ABC University and you are asked to vote on the rule related to the unauthorized use of personal computing devices in the classroom. How would be your vote?

1. Please indicate your voting decision by SELECTING ONE OF THE OPTIONS below:

Yes, students should be allowed to use their personal computing device without permission from the instructor during class time

(1) No, students should not be allowed to use their personal computing device without permission from the instructor during class time.

Please answer the following questions with regard to your voting decision: Please SELECT THE OPTION that best describes the degree to which you DISAGREE or AGREE with each of the following statements.

\begin{tabular}{|c|c|c|c|c|c|c|c|}
\hline & $\begin{array}{c}\text { Strongly } \\
\text { Disagree } \\
\text { (1) }\end{array}$ & $\begin{array}{l}\text { Disagree } \\
\text { (2) }\end{array}$ & $\begin{array}{l}\text { Somewhat } \\
\text { Disagree } \\
\text { (3) }\end{array}$ & $\begin{array}{l}\text { Neither } \\
\text { Agree nor } \\
\text { Disagree } \\
\text { (4) }\end{array}$ & $\begin{array}{l}\text { Somewhat } \\
\text { Agree (5) }\end{array}$ & Agree(6) & $\begin{array}{r}\text { Strongly } \\
\text { Agree(7) }\end{array}$ \\
\hline $\begin{array}{l}\text { 2. I am confident in my } \\
\text { decision }\end{array}$ & 0 & 0 & 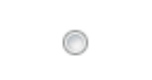 & ○ & $\bigcirc$ & 0 & ○ \\
\hline $\begin{array}{l}\text { 3. I am confident I made the } \\
\text { correct decision }\end{array}$ & ○ & ○ & ○ & O & $\bigcirc$ & ○ & $\odot$ \\
\hline $\begin{array}{l}\text { 4. I feel confident about my } \\
\text { vote }\end{array}$ & O & 0 & ○ & O & 0 & O & $\odot$ \\
\hline
\end{tabular}


B. Please examine the following information related to the use of laptops at the ABC University.
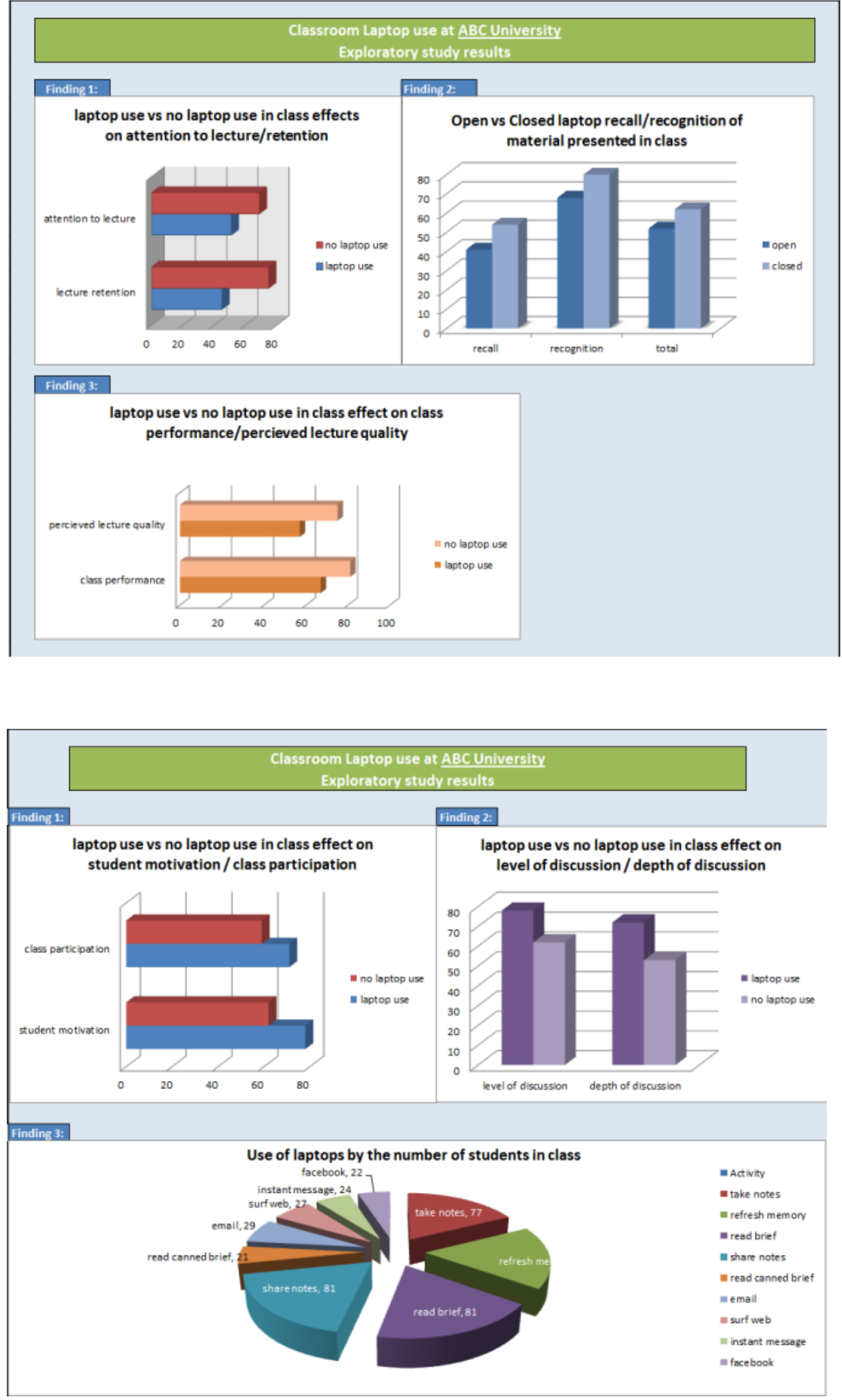
Decision Confidence, Information Usefulness, and Information Seeking Intention

C. Please, answer the following questions as they relate to the presented information and the decision of whether to allow the use of laptops in a classroom. Please SELECT THE OPTION that best describes the degree to which you DISAGREE or AGREE with each of the following statements

\begin{tabular}{l|l} 
5. I find the information useful & $\begin{array}{c}\text { Strongly } \\
\text { Disagree(1) Disagree(2) Disagree(3) }\end{array}$ \\
6. The information improves the \\
effectiveness of my decision \\
making \\
7. The information makes it \\
easier to make my decision \\
8. The information is useful in \\
my decision making \\
9. The information is useful to \\
me \\
10. I would like to seek more \\
information on the subject of \\
laptops in the classroom \\
11. I would like to look for more \\
evidence related to laptop use \\
in the classroom \\
12. I would be interested in \\
seeing more evidence related \\
to laptop use in the classroom \\
13. I would be interested in \\
examining more information \\
related to laptop use in the \\
classroom
\end{tabular}

D. Taking into account the presented evidence, how would you vote on the use of personal computing devices in the classroom? Please indicate your decision by voting yes or no.

Yes, students should be allowed to use their personal computing device without permission from the instructor during class time.

No, students should not be allowed to use their personal computing device without permission from the instructor during class time. 
In the light of the evidence presented, please answer the following questions regarding your current confidence in your voting decision (second round) by SELECTING THE OPTION that best describes the degree to which you DISAGREE or AGREE with each of the following statements.

\begin{tabular}{|c|c|c|c|c|c|c|c|}
\hline & $\begin{array}{c}\text { Strongly } \\
\text { Disagree } \\
\text { (1) }\end{array}$ & $\begin{array}{l}\text { Disagree } \\
\text { (2) }\end{array}$ & $\begin{array}{c}\text { Somewhat } \\
\text { Disagree } \\
\text { (3) }\end{array}$ & $\begin{array}{l}\text { Neither } \\
\text { Agree nor } \\
\text { Disagree } \\
(4)\end{array}$ & $\begin{array}{l}\text { Somewhat } \\
\text { Agree (5) }\end{array}$ & Agree(6) & $\begin{array}{r}\text { Strongly } \\
\text { Agree(7) }\end{array}$ \\
\hline $\begin{array}{l}\text { 2. I am confident in my } \\
\text { decision }\end{array}$ & ○ & O & 0 & 0 & ○ & ○ & ○ \\
\hline $\begin{array}{l}\text { 3. I am confident I made the } \\
\text { correct decision }\end{array}$ & 0 & 0 & ○ & 0 & 0 & ○ & 0 \\
\hline $\begin{array}{l}\text { 4. I feel confident about my } \\
\text { vote }\end{array}$ & 0 & ○ & O & ○ & ○ & O & O \\
\hline
\end{tabular}

24. Do you own a laptop
Yes
No

21. In an average week, I use a laptop in approximately....

\begin{tabular}{|c|c|c|c|c|c|c|}
\hline 0 & 1 Class & 2 Classes & 3 Classes & 4 Classes & 5 Classes & $\begin{array}{c}\text { More than } 5 \\
\text { Classes }\end{array}$ \\
\hline 0 & ○ & ○ & $\bigcirc$ & ○ & 0 & $\bigcirc$ \\
\hline
\end{tabular}

22. My Gender is:

$\begin{array}{cc}\text { Male } & \text { Female } \\ \bigcirc & \bigcirc\end{array}$

23. Age

$\begin{array}{cccccccc}18-21 & 22-25 & 26-29 & 30-33 & 34-37 & 38-41 & 42-45 & \text { Older than } 45 \\ & 0 & \bigcirc & \bigcirc & \bigcirc & \bigcirc & \bigcirc & \bigcirc\end{array}$




\section{APPENDIX B:}

\section{Information Seeking Survey Group Instrument (Non-Visual Group)}

A. Please read the following scenario related to the use of computers in classroom.

Many students bring their personal computing devices (e.g. laptops) to their classes and use them during lectures. Some professors feel that the unauthorized use of personal laptops by students during class time is disruptive to their learning. Some students and professors feel that the use of personal laptop actually enhances learning experience. Imagine that you are member of a student government body at the ABC University and you are asked to vote on the rule related to the unauthorized use of personal computing devices in the classroom. How would be your vote?

1. Please indicate your voting decision by SELECTING ONE OF THE OPTIONS below:

Yes, students should be allowed to use their personal computing device without permission from the instructor during class time

No, students should not be allowed to use their personal computing device without permission from the instructor during class time

Please answer the following questions with regard to your voting decision: Please SELECT THE OPTION that best describes the degree to which you DISAGREE or AGREE with each of the following statements.

\begin{tabular}{|c|c|c|c|c|c|c|c|}
\hline & $\begin{array}{c}\text { Strongly } \\
\text { Disagree } \\
\text { (1) }\end{array}$ & $\begin{array}{l}\text { Disagree } \\
\text { (2) }\end{array}$ & $\begin{array}{c}\text { Somewhat } \\
\text { Disagree } \\
\text { (3) }\end{array}$ & $\begin{array}{l}\text { Neither } \\
\text { Agree nor } \\
\text { Disagree } \\
\text { (4) }\end{array}$ & $\begin{array}{l}\text { Somewhat } \\
\text { Agree (5) }\end{array}$ & Agree(6) & $\begin{array}{r}\text { Strongly } \\
\text { Agree(7) }\end{array}$ \\
\hline $\begin{array}{l}\text { 2. I am confident in my } \\
\text { decision }\end{array}$ & ○ & ○ & ○ & 0 & ○ & $\bigcirc$ & 0 \\
\hline $\begin{array}{l}\text { 3. I am confident I made the } \\
\text { correct decision }\end{array}$ & ○ & 0 & 0 & 0 & 0 & ○ & 0 \\
\hline $\begin{array}{l}\text { 4. I feel confident about my } \\
\text { vote }\end{array}$ & ○ & ○ & ○ & 0 & ○ & ○ & ○ \\
\hline
\end{tabular}


B. Please examine the following information related to the use of laptops at the ABC University.

\section{Classroom Laprtop us at ABC University \\ Exploratory study results}

Finding 1:

Online concent is more stimulating than traditional classroom distractors (e.g., passing noted or talking) and interferes even more with students ability to learn material. Students actively seeking course-related material show a suprisingly decreased ability to balance their attention between the lecture content and their focused searching online

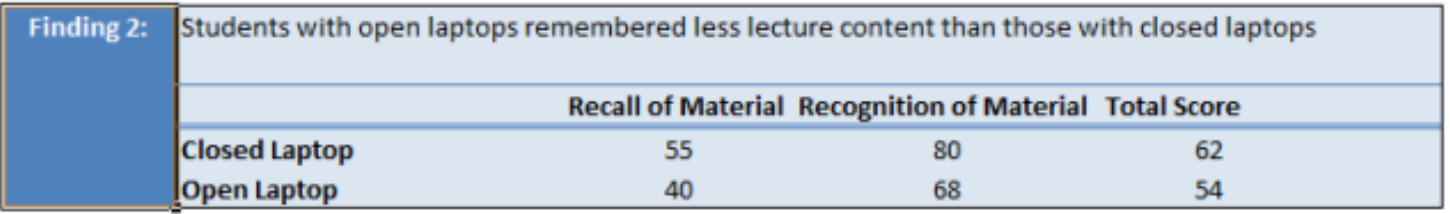

Finding 3: The more students used their laptops, the lower was their class performance was, and the less clear the lectures seemed to be.

Please examine the data collected from ABC University and then answer the following questions as they relate to the information provided.

\section{Classroom Laprtop us at $\mathrm{ABC}$ University Exploratory study results}

Laptops allow for increased ease and speed of note-taking and engagement with online sources related to the course material. Laptops can also be used to facilitate faculty-student interaction and increase rates of inclass participation and student motivation.

\begin{tabular}{|c|c|c|}
\hline \multirow[t]{10}{*}{ Finding 2: } & \multicolumn{2}{|c|}{ Students reported that they frequently use their laptops in class for the following activities: } \\
\hline & Activity & $\begin{array}{l}\text { Percentage of students } \\
\text { reporting the activity. }\end{array}$ \\
\hline & Take notes & $82 \%$ \\
\hline & Refresh memory with notes & $74 \%$ \\
\hline & Read self prepared brief & $69 \%$ \\
\hline & Share notes with classmates & $29 \%$ \\
\hline & read canned brief & $21 \%$ \\
\hline & Email & $21 \%$ \\
\hline & Surf Web & $21 \%$ \\
\hline & Instantmessage & $18 \%$ \\
\hline
\end{tabular}

Finding 3: Students who use laptops a lot in class are more likely to contribute to class discussions amd those discussions tend to be more in depth. 
Decision Confidence, Information Usefulness, and Information Seeking Intention

C. Please, answer the following questions as they relate to the presented information and the decision of whether to allow the use of laptops in a classroom. Please SELECT THE OPTION that best describes the degree to which you DISAGREE or AGREE with each of the following statements

\begin{tabular}{l|l} 
5. I find the information useful & $\begin{array}{c}\text { Strongly } \\
\text { Disagree(1) Disagree(2) Disagree(3) }\end{array}$ \\
6. The information improves the \\
effectiveness of my decision \\
making \\
7. The information makes it \\
easier to make my decision \\
8. The information is useful in \\
my decision making \\
9. The information is useful to \\
me \\
10. I would like to seek more \\
information on the subject of \\
laptops in the classroom \\
11. I would like to look for more \\
evidence related to laptop use \\
in the classroom \\
12. I would be interested in \\
seeing more evidence related \\
to laptop use in the classroom \\
13. I would be interested in \\
examining more information \\
related to laptop use in the \\
classroom
\end{tabular}

D. Taking into account the presented evidence, how would you vote on the use of personal computing devices in the classroom? Please indicate your decision by voting yes or no.

Yes, students should be allowed to use their personal computing device without permission from the instructor during class time.

No, students should not be allowed to use their personal computing device without permission from the instructor during class time. 
In the light of the evidence presented, please answer the following questions regarding your current confidence in your voting decision (second round) by SELECTING THE OPTION that best describes the degree to which you DISAGREE or AGREE with each of the following statements.

\begin{tabular}{|c|c|c|c|c|c|c|c|}
\hline & $\begin{array}{c}\text { Strongly } \\
\text { Disagree } \\
\text { (1) }\end{array}$ & $\begin{array}{l}\text { Disagree } \\
\text { (2) }\end{array}$ & $\begin{array}{c}\text { Somewhat } \\
\text { Disagree } \\
\text { (3) }\end{array}$ & $\begin{array}{l}\text { Neither } \\
\text { Agree nor } \\
\text { Disagree } \\
(4)\end{array}$ & $\begin{array}{l}\text { Somewhat } \\
\text { Agree (5) }\end{array}$ & Agree(6) & $\begin{array}{r}\text { Strongly } \\
\text { Agree(7) }\end{array}$ \\
\hline $\begin{array}{l}\text { 2. I am confident in my } \\
\text { decision }\end{array}$ & ○ & O & 0 & 0 & ○ & ○ & ○ \\
\hline $\begin{array}{l}\text { 3. I am confident I made the } \\
\text { correct decision }\end{array}$ & 0 & 0 & ○ & 0 & 0 & ○ & 0 \\
\hline $\begin{array}{l}\text { 4. I feel confident about my } \\
\text { vote }\end{array}$ & 0 & ○ & O & ○ & ○ & O & O \\
\hline
\end{tabular}

24. Do you own a laptop
Yes
No

21. In an average week, I use a laptop in approximately....

\begin{tabular}{|c|c|c|c|c|c|c|}
\hline 0 & 1 Class & 2 Classes & 3 Classes & 4 Classes & 5 Classes & $\begin{array}{c}\text { More than } 5 \\
\text { Classes }\end{array}$ \\
\hline 0 & ○ & ○ & $\bigcirc$ & ○ & 0 & $\bigcirc$ \\
\hline
\end{tabular}

22. My Gender is:

Male

○
Female

○

23. Age

\begin{tabular}{|c|c|c|c|c|c|c|c|}
\hline $\begin{array}{c}18-21 \\
0\end{array}$ & $\begin{array}{c}22-25 \\
\bigcirc\end{array}$ & $\begin{array}{c}26-29 \\
\bigcirc\end{array}$ & $\begin{array}{c}30-33 \\
\bigcirc\end{array}$ & $\begin{array}{c}34-37 \\
\bigcirc\end{array}$ & $\begin{array}{c}38-41 \\
\end{array}$ & $\begin{array}{c}42-45 \\
\bigcirc\end{array}$ & Older than 45 \\
\hline
\end{tabular}




\section{Biographies}

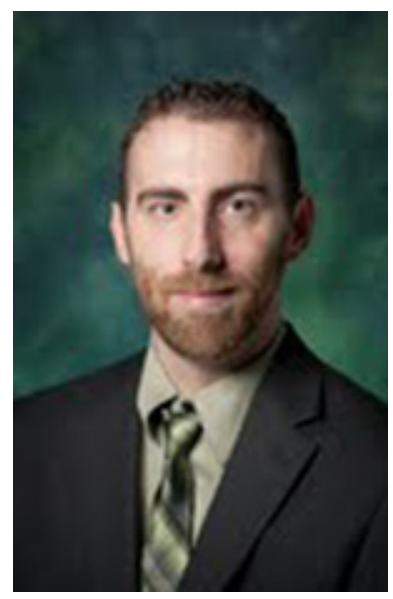

Brandon K. Phillips is currently a Ph.D. student in the Information Technology and Decision Sciences Department at the University of North Texas. Prior to UNT, he was a systems analyst at Caesars Entertainment. He obtained his B.A. in information systems from Southwestern Oklahoma State University, and M.S. in MIS from the University of Nevada Las Vegas. His research interests include business intelligence, data visualization, interface design, and social media. He can be reached at Brandon.Phillips@unt.edu

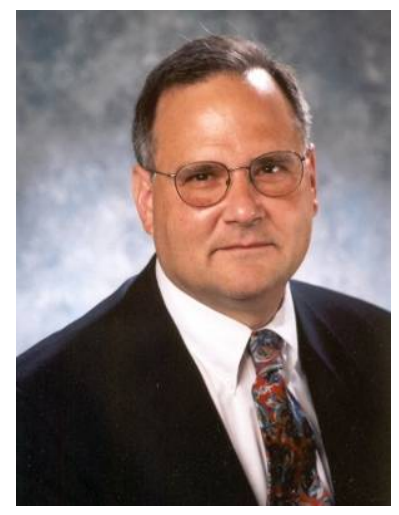

Victor R. Prybutok is a Regents Professor of Decision Sciences in the Information Technology and Decision Sciences Department and Associate Dean of the Toulouse Graduate School at the University of North Texas. He received, from Drexel University, his B.S. with High Honors in 1974, a M.S. in Bio-Mathematics in 1976, a M.S. in Environmental Health in 1980, and a Ph.D. in Environmental Analysis and Applied Statistics in 1984. Dr. Prybutok is an American Society for Quality certified quality engineer, certified quality auditor, certified manager of quality / organizational excellence, and an accredited professional statistician (PSTAT ${ }^{\circledR}$ ) by the American Statistical Association. Dr. Prybutok has authored over 135 journal articles, several book chapters, and more than 150 conference presentations in information systems measurement, quality control, risk assessment, and applied statistics. In addition, he serves on the editorial board of the Quality Management Journal. Victor's email is prybutok@unt.edu

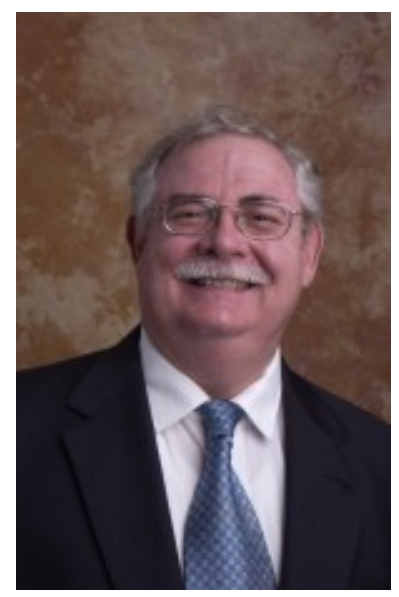

Daniel A. Peak is an associate professor in information technology in the Information Technology and Decision Sciences Department, College of Business Administration at the University of North Texas. He received his Ph.D. in 1994 from UNT with majors in Information Systems and in Finance. He also has several degrees in piano performance, and has studied with well-known pianists and artists. He is an editor of the Journal of IT Cases and Applications Research. Dr. Peak has more than 20 years of IT consulting and planning experience working for executives of Fortune 500 companies, and has won and directed numerous production projects and research grants. He is a member of the Decision Science Institute and Association for Information Systems and has publications in Informing Science, Information and Management, Information Systems Management, and other journals. Dan can be reached by email at peak@unt.edu 